\title{
Analysis of Novel Soybean Sprout Allergens That Cause Food-Induced Anaphylaxis
}

\author{
Ryoko Nakagawara ${ }^{1,2 *}$, Yasuharu Itagaki ${ }^{1,3,5}$, Masumi Kohno ${ }^{2}$, Setsuko Matsukura ${ }^{2}$, Maki Miyazawa ${ }^{4}$, \\ Kenichi Kumasaka ${ }^{4}$, Takashi KoJima ${ }^{4}$, Zenro IkeZawa $^{1}$ and Michiko Ainara ${ }^{1}$ \\ ${ }^{I}$ Department of Environmental Immuno-Dermatology, Yokohama City University, Graduate School of Medicine, Kanagawa, Japan \\ ${ }^{2}$ Yokohama City University Medical Center, Kanagawa, Japan \\ ${ }^{3}$ Department of Health and Nutrition, Hokkaido Bunkyo University, Hokkaido, Japan \\ ${ }^{4}$ Kanagawa Prefectural Institute of Public Health, Kanagawa, Japan \\ ${ }^{5}$ Kanagawa Academy of Science and Technology, Kanagawa, Japan
}

Received January 27, 2013; Accepted March 4, 2013

Several soybean- and soy product-based allergens have been reported. However, a full analysis of soybean sprout allergens remains to be conducted. Soybean sprout allergy is related to soy intolerance. Here we report a case of anaphylaxis induced by soybean sprouts in a 49-year-old woman. We performed a skin prick test, allergen-specific IgE identification using microarray assay (ImmunoCAP ${ }^{\circledR}$-ISAC), SDS-PAGE, and immunoblotting for allergen analysis. The ImmunoCAP ${ }^{\circledR}$-ISAC microarray assay detected Gly $\mathbf{m} 4$ in the soybean sprout. However, immunoblotting revealed two 100-kDa protein bands that did not correspond to Gly $\mathrm{m} 4$ (17 kDa). Therefore, we propose that this patient was not only sensitized to the Gly $\mathrm{m} 4$ allergen, but also to the novel 100-kDa protein.

Keywords: food allergy, soybean sprout, allergen analysis, anaphylaxis

\section{Introduction}

Soybean sprouts are the budded form of soybeans. Soybeans are thought to have arrived to Japan from China during the Heian period. It is believed that in the early stages of its propagation, the dried form of soybean sprouts was used for medical purposes. Because of its excellent nutritive value, it has been used as a vegetable for approximately the past 100 years. Soybean consumption has recently increased, and it has become a common vegetable.

Over time, many cases of food allergy have been reported, including those resulting from soybean consumption, which were reported after identification of the allergen protein. However, there are few reports on allergy resulting from soybean sprout consumption. Although soybean sprout allergy may be related to soy intolerance, there is insufficient data to confirm this.

Here, we examined a case of soybean sprout allergy and attempted to identify the allergen protein by skin prick test, allergen-specific IgE identification, and microimmunoassay.

*To whom correspondence should be addressed. E-mail: naname1045@yahoo.co.jp

\section{Materials and Methods}

For this research, we were advised of any ethical issues by the university hospital and obtained written informed consent from the patient prior to initiation of the study

Patient A 49-year-old woman with a history of seasonal rhinoconjunctivitis experienced two episodes of severe systemic anaphylaxis, characterized by nasal and orbital pruritus, facial angioedema and dyspnea, approximately 2 min after ingesting green (immature) soybeans and soybean sprouts. Before these episodes, she had reported intraoral and periorbital pruritus immediately after consuming abura-age (fried thin tofu) and yuba (the protein film layer on the surface of heated soy milk). However, she reported no adverse reactions to bean curd or boiled mature soybeans.

Serum samples Serum samples were obtained from the patient and stored at $-80^{\circ} \mathrm{C}$. Mixed sera samples from more than 100 healthy individuals were used as controls.

Allergen preparations Mature soybean cv. Hayahikari (defatted with acetone) and soybean sprouts (stems, roots, and stems plus roots) were ground, and the resulting powders ( $1 \mathrm{~g}$ each) were extracted with $0.05 \mathrm{~mol} / \mathrm{L}$ Tris- $\mathrm{HCl}$ containing $3 \mathrm{~mol} / \mathrm{L} \mathrm{NaSCN}$ (pH 7.5) and shaken for $5 \mathrm{~min}$ at room temperature. The samples were centrifuged at $15,000 \mathrm{~g}$ for 
$40 \mathrm{~min}$, and the supernatants were stored at $4^{\circ} \mathrm{C}$.

Skin testing All skin prick tests were performed using whole soybean, soybean sprout, and soybean products. Saline solution and histamine hydrochloride $(10 \mathrm{mg} / \mathrm{mL})$ were used as negative and positive controls, respectively. All skin tests were read at $15 \mathrm{~min}$, compared with positive histamine controls, and scored $(1+=25 \%$ of the swollen area in the histamine control; $2+=50 \% ; 3+=100 \%$; and $4+=200 \%$ ).

Allergen-specific IgE identification Allergen-specific IgE levels against pollen, Gly m 4 (PR-10), Gly m 5 ( $\beta$-conglycinin), Gly m 6 (glycinin), soybean, pea, and peanut were measured by the fluoroenzymatic method (CAP System, Pharmacia Diagnostics AB, Uppsala, Sweden) according to the manufacturer's instructions.

Microarray assay The PR-10 family antigens (Gly m 4, Aln g 1, and Bet $\mathrm{v} 1$ ) were evaluated using a microarray assay (ImmunoCAP ${ }^{\circledR}$-ISAC; Pharmacia Diagnostics AB) according to the manufacturer's instructions. Aln $\mathrm{g} 1$ is a major allergen in the pollen of Alnus glutinosa (European alder), while Bet $\mathrm{v} 1$ is a major allergen in the pollen of Betula pendula (European white birch).

SDS-PAGE analysis Extracts of soybean sprout stem, soybean sprout stem and root, soybean sprout root, and mature soybean (defatted) were separated by SDS-PAGE using $10 \%-15 \%$ acrylamide separating gels and $4 \%$ stacking gels. All extracts were dissolved 1:1 in nonreducing sample buffer and sample buffer containing $5 \%$ 2-mercaptoethanol at $20^{\circ} \mathrm{C}$ without heating (the extracts were heated for $5 \mathrm{~min}$ at $100^{\circ} \mathrm{C}$ in a further experiment, as described in the in Discussion section). Each allergen extract sample $(15 \mu \mathrm{L})$ was electrophoresed at $150 \mathrm{~V}$ for approximately $85 \mathrm{~min}$, after which the gels were stained with Coomassie brilliant blue.

Immunoblot analysis Separated proteins from the allergen extracts were electrophoretically transferred to polyvinylidene difluoride membranes, which were then incubated with $5 \mathrm{~mL}$ of 1:10 diluted serum in incubation buffer, shaken for $1 \mathrm{~h}$ at $37^{\circ} \mathrm{C}$, washed, and incubated with monoclonal anti-human IgE antibody (1:20,000; Bio-Rad Laboratories, Hercules, CA, USA) for $3 \mathrm{~h}$. Next, the membranes were washed and incubated with alkaline phosphatase-labeled anti-goat IgG antibody (1:20,000; Bio-Rad Laboratories) for 3 $\mathrm{h}$. The membranes were washed again, treated with enhanced chemiluminescence substrate (ECL plus Western Blotting Detection Reagents, GE Healthcare UK Ltd., Buckinghamshire, UK), and incubated for $10 \mathrm{~min}$. We used $\mathrm{ECL}^{\mathrm{TM}}$ MiniCamera to capture images (GE Healthcare UK Ltd.) and exposed the membranes for $5 \mathrm{~min}$.

\section{Results}

Skin testing The patient tested positive in the skin prick test for soy milk, tofu, green soybean, and root of soybean sprout, but negative to abura-age, stem of soybean sprout, bean of soybean sprout, canned boiled soybean, soy oil, kinako (soy flour), okara (soy fiber), and fermented soy products (soy sauce, miso, and natto) (Table 1.). Notably, she tested negative for hard-type yuba in the first test and positive for soft-type yuba in the second test. It was thought that this result originated because of the denatured condition of the protein caused by heating of soy milk.

Allergen-specific IgE identification Specific IgE antibodies against cedar pollen, alder pollen, birch pollen, and Gly $\mathrm{m} 4$ (PR-10) were detected using the CAP system, while specific IgE antibodies against Gly $\mathrm{m} 5$ ( $\beta$-conglycinin), Gly m 6 (glycinin), and soybean were not (Table 2.). The micro-

Table 1. Skin prick test results.

The skin prick test was administered on the forearm of the patient, and results were visualized 15 min later.

\begin{tabular}{lcc}
\hline & 1 st & $\begin{array}{c}2 \mathrm{nd} \\
\text { (after 19 months) }\end{array}$ \\
\hline Soybean milk & $2+$ & \\
Tofu & $2+$ & \\
Abura-age & Negative & \\
Green soybean & $2+$ & $2+$ \\
Yuba & Negative & $2+$ \\
Soybean sprout (root) & & $2+$ \\
Soybean sprout (stem) & & Negative \\
Soybean sprout (bean) & & Negative \\
Canned boiled soybean & & Negative \\
Soybean oil & & Negative \\
Kinako, soybean flour & & Negative \\
Okara, soybean filder & & Negative \\
Soy sauce, fermented souybeans sauce & Negative & \\
Miso, fermented souybean paste & & Negative \\
Natto, fermented soybean & Negative & Negative \\
\hline
\end{tabular}

Table 2. Allergen-specific IgE analysis results using the CAP system.

The patient was subjected to blood sample collection and medical examination on the initial day and 19 months later.

\begin{tabular}{lcc}
\hline & $\begin{array}{c}(\mathrm{UA} / \mathrm{mL})(\text { class }) \\
1 \mathrm{st}\end{array}$ & $\begin{array}{c}(\mathrm{UA} / \mathrm{mL}) \text { (class) } \\
\text { 2nd (after 19 months) }\end{array}$ \\
\hline Total IgE & 17.0 & 28.0 \\
Cedar pollen & $3.00(2)$ & $9.22(3)$ \\
Alder pollen & $3.82(3)$ & $5.00(3)$ \\
Birch pollen & $7.05(3)$ & $7.15(3)$ \\
Mugwort pollen & $\leq 0.34(0)$ & \\
Ragweed pollen & $\leq 0.34(0)$ & \\
Orchaerd grass pollen & $\leq 0.34(0)$ & \\
Gly m 4 (PR-10) & $2.43(2)$ & $\leq 0.34(0)$ \\
Gly m 5 ( $\beta$-Conglycinin) & $\leq 0.34(0)$ & \\
Gly m 6 (Glycinin) & $\leq 0.34(0)$ & \\
Soybean & $\leq 0.34(0)$ & $\leq 0.34(0)$ \\
Pea & $\leq 0.34(0)$ & \\
Peanut & $\leq 0.34(0)$ & \\
Almond & $\leq 0.34(0)$ & \\
Latex & & \\
\hline
\end{tabular}


array assay (ImmunoCAP ISAC ${ }^{\circledR}$ ) revealed that the patient exhibited a positive reaction to the PR-10 family antigens (Gly $\mathrm{m} 4$, Aln g 1, and Bet v 1). The patient's total IgE level was considered as the reference value. Specific IgE antibodies against cedar pollen, alder pollen, and birch pollen levels were higher in the second test than in the first test.

SDS-PAGE and immunoblotting SDS-PAGE analysis revealed bands with molecular weights of $20-150 \mathrm{kDa}$. The soybean sprout stem (lane 1) showed 11 bands, the stem and root (lane 2) showed 11 bands, the root (lane 3) showed 9 bands, and defatted soybean (lane 4) showed 6 bands. SDSPAGE analysis showed multiple protein bands with molecular weights of $6-150 \mathrm{kDa}$ for each part of the soybean sprout and mature soybean. Immunoblotting of the patient's serum indicated that the soybean sprout stem was negative, whereas the stem and root were positive for the $100-\mathrm{kDa}$ protein. The root, alone, was positive for the $100-\mathrm{kDa}$ protein. Therefore, the protein that existed in the root of the soybean sprout was considered to be the antigen protein (Fig. 1.).

\section{Discussion}

As far as we know the protein (allergen) responsible for soybean sprout allergy has not been reported until now. Thus, the allergen that positively reacted in the immunoblotting method in this study is considered novel. In an earlier report, soybean sprout and soybean allergies were found to be associated. Thus, we thought it relevant to study soybean sprout and soybean allergies, because the patient in this case was positive for allergy to soybean related food.

Various types of allergic reactions have been reported in soybean-sensitized patients. Class 1 food allergy occurs by sensitization through the digestive tract and induces immediate reactions such as urticaria and anaphylaxis. Several class 1 allergens from soybeans have been identified, including $\beta$-conglycinin (Gly m 5), P34, an oil-body-associated protein (Gly m Bd30K), and a glycinin A3 subunit (Gly m 6; Adachi et al., 2006). In addition, an immediate reaction to class 2 food allergens, which occurs through pollen-food crossreactivity and is established after developing pollinosis, has also been observed in patients with soy allergy (Fukuda et al., 2007). Recent reports have indicated that soybean and its products may also induce respiratory allergy via inhalation, as well as systemic reactions (Kosma et al., 2011). Soy antigens that cause class 2 food allergies include the PR-10 family (Gly m 4), soy profilin (Gly m 3), and oleosin (KleineTebbe et al., 2002).

The allergenicity of soybean essentially resides in the protein fraction. Approximately $90 \%$ of soybean storage proteins are salt-soluble globulins, with the remainder being water-soluble albumins. Soy proteins can be separated into

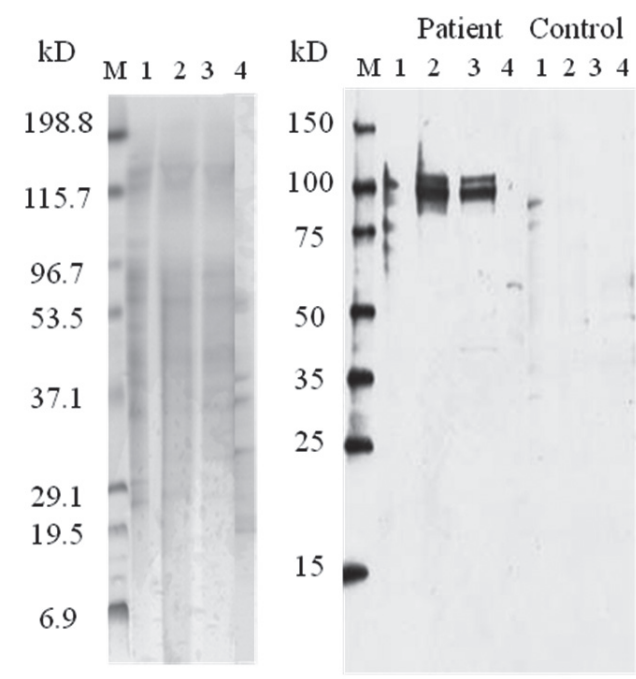

M: Marker

1: soybean sprout stem

2: soybean sprout stem and root

3: soybean sprout root

4: mature soybean (defatted with acetone)

Fig. 1. Results of SDS-PAGE and immunoblotting.

After electrophoresis, soybean sprout and soybean proteins were transferred to a blotting membrane and subjected to immunoblotting using patient and control sera.

four fractions, with approximate Svedberg coefficients of 2, 7, 11, and $15 \mathrm{~S}$. The identification and characterization of specific proteins linked to soy allergy has been the focus of many studies (Table 3.). In 1995, Ogawa et al. first reported several major class 1 allergens from soybean, which included three $7 \mathrm{~S}$ proteins, namely Gly $\mathrm{m}$ Bd 30K (P34, an oil-bodyassociated protein; $34 \mathrm{kDa}$ ), Gly $\mathrm{m} \mathrm{Bd} 68 \mathrm{~K}$ ( $\beta$-conglycinin $\alpha$-subunit; $68 \mathrm{kDa}$ ), and Gly $\mathrm{m} \mathrm{Bd} 28 \mathrm{~K}$ storage protein of the vicilin family; $28 \mathrm{kDa}$ ). Gly $\mathrm{m} \mathrm{Bd} 30 \mathrm{~K}$ showed considerable sequence similarity to the thiol proteinase of the papain family, including the allergenic thiol proteinase Der $\mathrm{p} 1$ from house dust mites. However, the specific epitopes were different.

In Europe and the USA, since soybeans are seldom eaten, most reports deal with class 2 soy allergy. The soybean hull was identified as a source of aeroallergens that caused soyinduced epidemic asthma, and the hull components responsible for respiratory allergies were identified as Gly $\mathrm{m} 1$ (Gly m 1.0101, 4.2 kDa; Gly m 1.0102, 3.9 kDa) and Gly $\mathrm{m} 2$, both of which belong to a lipid- transfer family of allergens. A partial N-terminal sequence of Gly $\mathrm{m} 2$ exhibited $71 \%$ homology with a storage protein from cowpea and $64 \%$ homology with a disease-response protein from green pea. Nevertheless, these low molecular weight soybean hull aeroallergens were not found to be responsible for the occupational asthma caused by soy flour in bakers. Gly $\mathrm{m} 3$, which is a $14.1-\mathrm{kDa}$ soy profilin, was found to be homologous to 
Table 3. A list of allergy-associated soybean proteins (allergens) The detected allergens in this study were compared to previously reported soybean allergens.

\begin{tabular}{|c|c|c|c|c|c|}
\hline IgE-binding proteins & Allergen nomenclature & Molecular weight $(\mathrm{kDa})$ & Family & Food allergy class & Note \\
\hline B-Conglycinin & Gly m 5 & $\begin{array}{l}68 \text { ( } \alpha \text { subunit }) \\
66 \text { ( } \alpha \text { ' subunit }) \\
50 \text { ( } \beta \text { subunit })\end{array}$ & $\begin{array}{l}\text { Major storage protein } \\
\text { 7S globrin } \\
\text { Saccharide binding protein }\end{array}$ & 1 & \\
\hline Glycinin A3subunit & Gly m 6 & 43 & $\begin{array}{c}\text { Major storage protein } \\
11 \mathrm{~S} \text { globrin }\end{array}$ & 1 & \\
\hline P34 & Gly m Bd30k & $\begin{array}{c}30 \\
\text { (SDS-PAGE:34) }\end{array}$ & $\begin{array}{l}\text { Maturing seed vacuolar thiol } \\
\text { protease }\end{array}$ & 1 & \\
\hline Gly m Bd28kD & Gly m Bd28k & 28 & $\begin{array}{l}\text { Vicilin family } \\
\text { (storage protein) }\end{array}$ & 1 & \\
\hline Oleosin & Not assigned & $23-24$ & Oilbody binding protein & 2 & \\
\hline Trypsin inhibitor & Gly m TI & $18-20$ & Protease inhibitor & 1 & \\
\hline SAM22 & Gly m 4 (IUIS)* & 16.8 & Bet v 1 homolog PR-10 family & 2 & This case \\
\hline Profilin & Gly m 3 (IUIS) & 14.1 & Profilin (actin adapting protein) & 2 & \\
\hline Unknown & Gly m 2 (IUIS) & 8 & Storage protein & Hull allergen & \\
\hline Unknown & $\begin{array}{l}\text { Gly m } 1.0101 \\
\text { Gly m } 1.0102\end{array}$ & $\begin{array}{l}4.2 \\
3.9\end{array}$ & Lipid transfer protein & Hull allergen & \\
\hline $2 \mathrm{~S}$ albumin & Not assigned & $\begin{array}{l}9 \text { (large subunit) } \\
5 \text { (small subunit) }\end{array}$ & $\begin{array}{l}\text { Storage protein } \\
\text { (proramine super family) }\end{array}$ & Unknown & \\
\hline NEW? & & 100 & & $?$ & This case \\
\hline
\end{tabular}

*IUIS:International union of Immunological Societies official allergen nomenclature.

Bet $\mathrm{v} 2$, a birch pollen allergen with a sequence identity of $73 \%$, and 11 other plant profilins with a 69 to $88 \%$ identity. Gly $\mathrm{m} 4$ is a $16.8-\mathrm{kDa}$ PR-10 SAM22 (starvation-associated message 22) protein from soybean, which has a sequence identity of $50 \%$ with Bet v 1 (a major allergen in birch pollen). Severe anaphylactic reactions have been reported in birch pollinotics after ingestion of soy protein isolates. For example, Kleine-Tebbe et al. (2002) reported that $85 \%$ of such patients had specific IgE antibodies against SAM22. More recently, Mittag et al. (2004) revealed that 96\% of patients who reacted to Bet $\mathrm{v} 1$ were also positive for Gly $\mathrm{m}$ 4-specific IgE. These reports confirmed that Gly $\mathrm{m} 4$ is the major soy allergen for patients allergic to birch pollen and that soybean is an additional birch pollen-related allergenic food. Further, Moriyama et al. (2005) reported that a 23 $24-\mathrm{kDa}$ soy protein was the allergen responsible for oral allergy syndrome and anaphylaxis to soy milk, and they identified the allergenic soy protein as oleosin, which exists in the lipid membrane of soybean cells.

We propose that our patient had a class 2 food allergy because she experienced seasonal rhinoconjunctivitis for a prolonged period and subsequently showed signs of food allergy. Her food allergy symptoms initially manifested as pollinosis, including nasal and orbital pruritus, and she also developed systemic reactions. Moreover, the patient was positive for serum-specific IgE antibodies against cedar pollen, alder pollen, birch pollen, and Gly $\mathrm{m} 4$. The specific IgE levels against cedar and alder pollen were higher in the second test than in the first test, probably because the first test was conducted in winter, while the second test was conducted in spring. We propose that the patient was first sensitized to pollen allergens of the PR-10 family and later developed an allergy to soy products because of their similar allergenic proteins. However, immunoblotting detected only $100-\mathrm{kDa}$ protein bands that did not correspond to Gly $\mathrm{m} 4$. Therefore, we believe that this patient was also sensitized to another allergenic protein that had a molecular weight of $100 \mathrm{kDa}$. Indeed, it is very rare to detect such a high-weight allergen, as $100-\mathrm{kDa}$ allergens have only been reported in Hymenoptera venom Api m 5, black abalone (Haliotis discus discus), papaya (Carica papaya) pollen, and buckwheat seed. However, C. papaya is not available in Japan, and this patient was able to consume $H$. discus discus without any allergic symptoms. The patient had never been stung by a bee; therefore, it is unlikely that she was sensitized to these allergens before she reacted to soybean sprouts. Importantly, the protein detected herein has not been previously reported; therefore, we present the possibility of a new soybean sprout allergen. Nevertheless, it remains unclear whether sensitization to this protein was caused by cutaneous or oral exposure. 
We believe that Gly $\mathrm{m} 4$ was not detected by immunoblotting because of the low level of IgE specific to Gly $\mathrm{m} 4$. We performed immunoblotting to test the patient's serum IgE levels against soybean sprout extract that had been heated for $5 \mathrm{~min}$ at $100^{\circ} \mathrm{C}$ and against raw soybean sprout parts (stems, beans, and roots). The patient's serum IgE antibodies reacted only with the raw soybean sprout root, suggesting that the allergenic protein denatured when exposed to heat and is contained only in the root. We attempted to purify and identify the $100-\mathrm{kDa}$ protein by chromatography and electrophoresis; however, we have not yet succeeded. In our future work, we will attempt to purify and identify this newly discovered allergen.

Acknowledgments This study was partly supported by a Grant-inAid from the Ministry of Education, Culture, Sports, Science, and Technology of Japan (No. 2159471).

\section{References}

Adachi, A., Moriyama, T., Shimizu, H. and Horikawa, T. (2006). Variety of soybean allergens and their relationships with various clinical subtypes of soybean allergy. J. Dermatoallergol., 14, 6472.

Adachi, A., Horikawa, T., Shimizu, H., Sarayama, Y., Ogawa, T., Sjolander, S., Tanaka, A. and Moriyama, T. (2008). Soybean $\beta$-conglycinin as the main allergen in a patient with food dependent exercise-induced anaphylaxis by tofu: food processing alters pepsin resistance. Clin. Exp. Allergy, 39, 167-173.

Crowell, D., Miliyakal, E., Russell, D. and Amasino, R. (1992). Characterization of a stress-induced, developmentally regulated gene family from soybean. Plant Mol. Biol., 18, 459-466.

Fukuda, K., Ochiai, T., Aikawa, M., Togo, K., Tomita, Y. and Moriyama, T. (2007). Oral allergy syndrome to soybean concomitant with birch pollen allergy: Clinical investigation and analysis of cross-reactive antigen. J. Environ. Dermatol. Cutan. Allergol., 1, 124-130.

Harada S., Nakamura A., Matsumaga A., Iijima M., Yoshizaki Y., Saito K., Adachi A. and Moriyama T. (2007). Three cases of soy milk allergy. J. Environ. Dermatol. Cutan. Allergol., 1, 31-38.

Holzhauser, T., Wackermann, O., Ballmer-Weber, B., BindslevJensen, C., Scibilia, J., Perono-Garoffo, L., Utsumi, S., Poulsen, L. and Vieths S. (2009). Soybean (Glycine max) allergy in Europe: Gly $\mathrm{m} 5$ ( $\beta$-conglycinin) and Gly $\mathrm{m} 6$ (glycinin) are potential diagnostic markers for severe allergic reactions to soy. J. Allergy. Clin. Immunol., 123, 452-458.

Iijima, S., Moriyama, T. and Ogawa, T. (2005). A case of anaphy- laxis due to soy milk; trial of detection of IgE-binding soybean proteins. J. Environ. Dermatol., 12, 184-191.

Kleine-Tebbe, J., Wangorsch, A., Vogel, L., Crowell, D., Haustein, U. and Vieths S. (2002). Severe oral allergy syndrome and anaphylactic reactions caused by a Bet v 1-related PR-10 protein in soybean, SAM22. J. Allergy. Clin. Immunol., 110, 797-804.

Kosma, P., Sjölander, S., Landgren, E., Borres, M. and Hedlin, G. (2011). Severe reactions after the intake of soy drink in birch pollen-allergic children sensitized to Gly m 4. Acta. Paediatr., 100, 305-306.

L'Hocine, L.I. and Boye, J. (2007). Allergenicity of soybean: new developments in identification of allergenic proteins, cross-reactivities and hypoallergenization technologies. Crit. Rev. Food. Sci. Nutr., 47, 127-143.

Mittag, D., Vieths, S., Vogel, L., Becker, W., Rihs, H., Helbling, A., Wuthrich, B. and Ballmer-Weber B. (2004). Soybean allergy in patients allergenic to birch pollen: Clinical investigation and molecular characterization of allergens. J. Allergy Clin. Immunol., 113, 148-154.

Morita, H., Kaneko, H., Ohnishi, H., Kondo, M., Matsui, E., Fukao, T. and Kondo, N. (2008). Analysis of antigenic proteins that trigger allergies and immunologic tolerance. Nihon Syouni Arerugi Gakkaishi, 22, 233-238.

Ogawa, T., Bando, N., Tsuji, H., Nishikawa, K. and Kitamura, K. (1995). $\alpha$-Subunit of $\beta$-conglycinin, an allergenic protein recognized by $\operatorname{IgE}$ antibodies of soybean-sensitive patients with atopic dermatitis. Biosci. Biotechnol. Biochem., 59, 831-833.

Ogawa, T., Samoto, M. and Takahashi, K. (2000). Soybean allergens and hypoallergenic soybean products. J. Nutr. Sci. Vitaminol., 46, 271-279.

Rihs, H.P., Chen, Z., Rueff, F., Peterson, A., Rozynek, P., Heimann, H. and Baur, X. (1999). IgE binding of the recombinant allergen soybean profilin (rGly $\mathrm{m} 3$ ) is mediated by conformational epitopes. J. Allergy Clin. Immunol., 104, 1293-1301.

Rodrigo, M., Morell, F., Helm, R., Swanson, M., Greife, A., Anto, J., Sunyer, J. and Reed C. (1990). Identification and partial characterization of the soybean-dust allergens involved in the Barcelona asthma epidemic. J. Allergy Clin. Immunol., 85, 778-84.

Sugano M. (2006). Is soybean oil allergenic? J. Jpn. Soc. Nutr. Food Sci., 59, 313-321.

Yagami, A, Inaba, Y, Kuno, Y, Tanaka, A, Sjolander, S, Saito, H. and Matsunaga, K. (2009). Two cases of pollen-food allergy syndrome to soy milk diagnosed by skin prick test, specific serum immunoglobulin E and microarray analysis. J. Dermatol., 36, 5055. 